\title{
Identification of the Requirements for the Effective Human Resource Development in the Health System
}

\author{
Fatemeh Kia ${ }^{1}$, Fraydoon Rahnamay Rood Poshti ${ }^{2} * \mathbb{D}$, Farhad Ghafari ${ }^{2}$, Seyed Ahmad Hashemii ${ }^{3}$, Nader Tavakoli ${ }^{4}$ \\ Received: 15 May 2021 \\ Published: 14 Oct 2021
}

\section{Abstract}

Background: The ultimate goal of development from the perspective of human capital development is to have a long, healthy, and creative life. This study aimed to identify the requirements for the effective human resource development in the health system.

Methods: This mixed method study was performed on 20 managers of Iran's health sector in the qualitative part to reach data saturation in qualitative research. The standard questionnaire of the health system consisting of 15 questions was distributed and collected among 302 managers of the health sector (senior and intermediate managers) and faculty professors who were selected by the stratified random sampling method using the Morgan table. Finally, for data analysis in the quantitative part, confirmatory factor analysis and modeling with partial least squares were used.

Results: The results showed that 4 of the requirements affecting human resource development were financial requirements with 13 components, service requirements with 14 components, educational requirements with 14 components, and partnership requirements with 7 components.

Conclusion: According to the results, it is suggested that in order to develop effective human resources in the health system, it is necessary to pay attention to the 4 financial, service, educational, and partnership requirements.

Keywords: Human Resource, Health System, Development

Conflicts of Interest: None declared

Funding: None

\section{*This work has been published under CC BY-NC-SA 1.0 license.}

Copyright $\bigcirc$ Iran University of Medical Sciences

Cite this article as: Kia F, Rahnamay Rood Poshti F, Ghafari F, Hashemi SA, Tavakoli N. Identification of the Requirements for the Effective Human Resource Development in the Health System. Med J Islam Repub Iran. 2021 (14 Oct);35:135. https://doi.org/10.47176/mjiri.35.135

\section{Introduction}

The slogan "Health for All" will not be realized in many countries, except by making reforms in the health sector and cooperation between human resource development and health (1). There is a universal consensus that human resources are the heart and soul of the health system everywhere. However, human resources are neglected in lowincome countries and are often poorly implemented in the health sector (2). In recent years, the health sector has been under more pressure than any other sector in terms of efficiency and effectiveness of the service provided because of continuous changes, strengthening marketoriented approach, and diversity of customer demand. Human resources are key factors in the success of the health sector in managing these complexities and challenges (3). Underdevelopment of human resources in the field of health can lead to the failure of any health policy (4). Therefore, health organizations are more dependent on their human resources than any other organization, and the quality and services of this sector strongly depend on the performance of human resources (5).

In particular, the development of human resources in the health sector are struggling with various issues and obstacles, such as lack of national strategy or program for the development of human resources, lack of prerequisites for human resource development, weak relationship between the teachings provided, and the needs of the country, gen-
Corresponding author: Dr Fraydoon Rahnamay Rood Poshti, Rahnama.roodposhti@gmail.com

1. Department of Management, UAE Branch, Islamic Azad University, Dubai, United Arab Emirates

2. Department of Economics, Sciences \& Research Branch, Islamic Azad University, Tehran, Iran

3. Department of Educational Sciences, Lamerd Branch, Islamic Azad University, Lamerd, Iran

4. Trauma and Injury Research Center, Iran University of Medical Sciences, Tehran, Iran $\uparrow$ What is “already known" in this topic:

Human resource development is very important in promoting the health system in all countries.

\section{$\rightarrow$ What this article adds:}

This article adds to our previous knowledge that 4 (financial, service, educational, and participation) requirements are necessary to develop human resources. 
eral and unrealistic policies in the field of human resources, insufficient attention to continuing education, and lack of constructive and effective communication between the Ministry of Health and Medical Education, universities, and other educational institutions in the health sector (1).

In recent years, the development of human resources has been considered in the health sector of Iran which aims to improve the competencies and capabilities of organizational human beings as well as self-development (57). Therefore, human resources and their level of development are of great importance in quality management of the health sector (8). For this reason, the development of human resources in the health sector in recent years has been recognized as a separate and distinct sector in the health sector. As in many developed countries, an independent structure in the structural part of the countries that is responsible for health and well-being has been formed as human resource development, which deals with policymaking to promote learning and human resource performance (9). The importance of human resource development in the health sector is incredible in such a way that much research has been done in this field and different results have been obtained. Asghari Sarem and Markazi Moghaddam performed a study entitled "Analysis of Success Crucial Factors for Human Resource Development at Health Sector" and identified 9 distinct mental patterns on the success of human resource development (5). Findings of a comparative study and a survey of experts in the research of Delgoashaee et al revealed that in the health sector of Iran, especially the Ministry of Health and Medical Education, human resource development should be among the requirements and should be supported by the highest organizational level with strategic commitment. Designing an appropriate structure and mechanism, adopting an approach, establishing physical facilities and resources, and providing human and financial resources, missions and tasks, attitude and knowledge development lead to increasing competitiveness and quality of services (10).

However, because of the importance of human resource development in the health sector, progress in it has been very slow, despite all the efforts of scientists and experts. This means that there is still a long way to go to implement human resource development in the health sector effectively. However, a review of research conducted inside and outside the country did not find any research that has identified the requirements for the development of effective human resources in the health sector. Therefore, the researcher seeks to answer the following question: What are the requirements for the development of effective human resources in the health system? It is hoped that this research will provide the authorities a clear vision of the basic requirements so that they could use it to efficiently plan human resource development programs.

\section{Methods}

This mixed method study was performed quantitatively and qualitatively. First, the purpose of the research was explained to the health system authorities and after obtaining their satisfaction, 20 senior and intermediate managers of the health sector based on their level of education, scientific knowledge (applied knowledge), and experience (managerial background) were interviewed with a semistructured method, which was analyzed by the Delphi method and led to the identification of some indicators. The method of sampling was based on the qualitative study to reach data saturation. Then, using the indicators approved by the experts in the quality section, the components and questions of the questionnaire were determined. Finally, a standard questionnaire of the health system, which consists of 15 questions and is scored based on a 7point Likert scale $(1=$ very low; $2=$ low; $3=$ low to medium, $4=$ medium; $5=$ medium to high; $6=$ high; $7=$ very high), was used to measure the appropriate model based on the performance of human resources. The questionnaire was distributed and collected among 302 managers of the health sector (senior and intermediate managers) and faculty professors who were selected by stratified random sampling method using the Morgan table. The reliability of the questionnaire was also confirmed using Cronbach's alpha (Table 1) and the validity was confirmed using content validity. Average Variance Extracted (AVE) was used to convergent validity and finding path coefficients and load factor of the research model (Fig. 1). Finally, for data analysis in the quantitative part, confirmatory factor analysis and modelling with PLS were used .It should be noted that having a university education in the field of the research topic, completion of the questionnaire, and answering all questions were the inclusion criteria; and not answering some questions of the questionnaire and not explaining the interview questions were the exclusion criteria.

\section{Results}

The results showed that most of the participants were men $(n=22 ; 74.2 \%)$. Also, most of the participants had a doctorate degree $(n=22 ; 69.3 \%)$ and were older than 50 years $(\mathrm{n}=165 ; 54.6 \%)$. Finally, most of the participants had 16 to 20 years of work experience $(n=102 ; 41.1 \%)$ (Tables 1 and 2).

The results of the qualitative part in this research showed that the priorities of health services management of human capital development in the model of health

\begin{tabular}{lcc}
\hline Variable & Cronbach's Alpha & Composite Reliability Coefficient \\
\hline Requirements for human capital financing & 0.843 & 0.894 \\
Requirements for improving human capital education & 0.784 & 0.847 \\
Requirements for improving the partnership of human capital & 0.784 & 0.850 \\
Requirements for managing health services of human capital & 0.952 & 0.956 \\
\hline
\end{tabular}




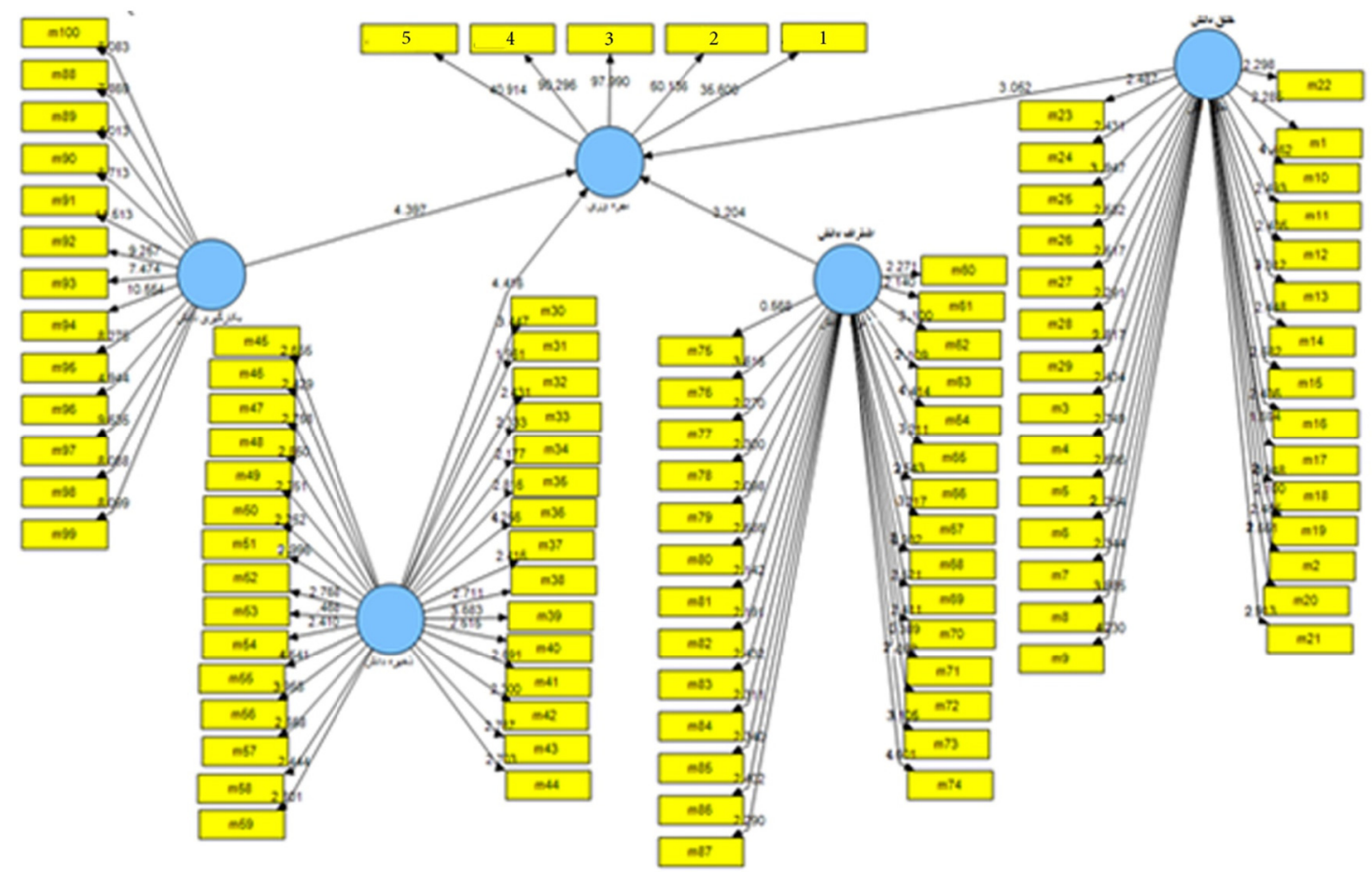

Fig. 1. Path Coefficients and Load Factor of the Research Model

economy system include the following components: position of prevention programs in health transformation plan; referral system; standardization and estimation of health manpower; evaluation of performance of health units and treatment centers; safety assessment in hospitals; costeffectiveness analysis of prescribing drugs; evaluation of family physician program; reasons for choosing private hospitals by people; evidence-based decision-making in equipping hospitals and using new treatment technology; level of hospital response and medical centers; new methods of hospital management; evaluation of the quality of services of medical centers; application of standards; and treatment protocols in hospitals (Table 3).

Human capital financing priorities in the model of health economics management system include different components as follows: improvement of national health accounts; health financing mechanisms; management information and decision support systems; methods of reducing out-of-pocket payments; costs of health services; improvement of project profitability; indicators of optimal allocation of financial resourices; outsourcing of health services resulting from new products; outsourcing of health services; establishment of new accounting systems in hospitals; operational budgeting; and charitable participation in health financing (Table 4).

Priorities for improving human capital education in the model of health economy management system include the following components: empowerment of health managers; strengthening research and development; improving the productivity of human resources; encouraging employee participation in knowledge exchange; creating sustainable participation in health service management requirements of human capital and staff development; standardization and estimation of health and human resources; comprehensive model for evaluating the performance of health workers; classification of new health jobs based on community needs; reducing life cycle and improving product development; methods to promote job motivation; health

Table 2. Demographic Characteristic of the Participants

\begin{tabular}{|c|c|c|c|}
\hline Variable & & Frequency & Percent \\
\hline \multirow[t]{3}{*}{ Gender } & Male & 224 & 74.2 \\
\hline & Female & 78 & 20.8 \\
\hline & Total & 302 & 100 \\
\hline \multirow[t]{4}{*}{ Education } & Bachelor's degree & 18 & 5.9 \\
\hline & Master's degree & 75 & 24.8 \\
\hline & Doctorate & 209 & 69.3 \\
\hline & Total & 302 & 100 \\
\hline \multirow[t]{5}{*}{ Age group } & $35-40$ & 49 & 16.3 \\
\hline & $41-45$ & 36 & 11.8 \\
\hline & $46-50$ & 52 & 17.3 \\
\hline & $>50$ & 165 & 54.6 \\
\hline & Total & 302 & 100 \\
\hline
\end{tabular}


Table 3. Weights of Variables in the Requirements of Health Services Management of Human Capital Development

\begin{tabular}{|c|c|c|c|c|}
\hline Requirements & Abbreviation & Level Weight & Criterion Weight & Final Weight \\
\hline Position of prevention programs in health transformation plan & M1 & 0.593 & 0.463 & 0.162 \\
\hline Referral system & M2 & 0.559 & 0.154 & 0.132 \\
\hline Standardization and estimation of health manpower & M3 & 0.516 & 0.084 & 0.099 \\
\hline Evaluation of performance of health units and treatment centers & M4 & 0.487 & 0.126 & 0.092 \\
\hline Safety assessment in hospitals & M5 & 0.452 & 0.094 & 0.084 \\
\hline Cost-effectiveness analysis of prescribing drugs & M6 & 0.440 & 0.114 & 0.070 \\
\hline Evaluation of family physician program & M7 & 0.416 & 0.158 & 0.061 \\
\hline Reasons for choosing private hospitals by people & M8 & 0.394 & 0.115 & 0.058 \\
\hline $\begin{array}{l}\text { Evidence-based decision-making in equipping hospitals and using } \\
\text { new treatment technology }\end{array}$ & M9 & 0.375 & 0.095 & 0.055 \\
\hline Level of hospital response and medical centers & M10 & 0.342 & 0.081 & 0.049 \\
\hline New methods of hospital management & M11 & 0.327 & 0.136 & 0.045 \\
\hline Evaluation of the quality of services of medical centers & M12 & 0.308 & 0.179 & 0.039 \\
\hline Application of standards and treatment protocols in hospitals & M13 & 0.287 & 0.091 & 0.037 \\
\hline
\end{tabular}

Table 4. Weights of Variables in the Requirements of Human Capital Financing

\begin{tabular}{|c|c|c|c|c|}
\hline Requirements & Abbreviation & $\begin{array}{c}\text { Level } \\
\text { Weight }\end{array}$ & $\begin{array}{c}\text { Criterion } \\
\text { Weight }\end{array}$ & $\begin{array}{c}\text { Final } \\
\text { Weight }\end{array}$ \\
\hline Improvement of national health accounts & A1 & 0.756 & 0.386 & 0.115 \\
\hline Health financing mechanisms & A2 & 0.744 & 0.251 & 0.102 \\
\hline Management information and decision support systems & A3 & 0.725 & 0.255 & 0.099 \\
\hline Methods of reducing out-of-pocket payments & A4 & 0.687 & 0.298 & 0.081 \\
\hline Costs of health services & A5 & 0.639 & 0.261 & 0.074 \\
\hline Improvement of project profitability & A6 & 0.606 & 0.189 & 0.069 \\
\hline Indicators of optimal allocation of financial resources & A7 & 0.579 & 0.146 & 0.087 \\
\hline Outsourcing of health services resulting from new products & A8 & 0.525 & 0.158 & 0.103 \\
\hline Establishment of new accounting systems in hospitals & A9 & 0.511 & 0.132 & 0.071 \\
\hline Outsourcing of health services & A10 & 0.494 & 0.098 & 0.026 \\
\hline Operational budgeting & A11 & 0.481 & 0.069 & 0.055 \\
\hline Charitable participation in health financing & A12 & 0.469 & 0.055 & 0.036 \\
\hline Effect of targeted subsidies on the health sector & A13 & 0.442 & 0.049 & 0.042 \\
\hline
\end{tabular}

Table 5. Weights of Variables in the Requirements of Improving Human Capital Education

\begin{tabular}{|c|c|c|c|c|}
\hline Requirements & Abbreviation & $\begin{array}{c}\text { Level } \\
\text { Weight }\end{array}$ & $\begin{array}{c}\text { Criterion } \\
\text { Weight }\end{array}$ & $\begin{array}{c}\text { Final } \\
\text { Weight }\end{array}$ \\
\hline Empowerment of health managers & V1 & 0.612 & 0.532 & 0.226 \\
\hline Strengthening research and development & $\mathrm{V} 2$ & 0.592 & 0.282 & 0.202 \\
\hline Improving the productivity of human resources & V3 & 0.573 & 0.244 & 0.187 \\
\hline Encouraging employee participation in knowledge exchange & V4 & 0.541 & 0.365 & 0.151 \\
\hline $\begin{array}{l}\text { Creating sustainable participation in health service management require- } \\
\text { ments of human capital and staff development }\end{array}$ & V5 & 0.527 & 0.088 & 0.132 \\
\hline Standardization and estimation of health and human resources & V6 & 0.479 & 0.189 & 0.115 \\
\hline Comprehensive model for evaluating the performance of health workers & V7 & 0.425 & 0.127 & 0.097 \\
\hline Classification of new health jobs based on community needs & V8 & 0.377 & 0.097 & 0.083 \\
\hline Reducing life cycle and improving product development & V9 & 0.342 & 0.089 & 0.076 \\
\hline Methods to promote job motivation & V10 & 0.318 & 0.135 & 0.052 \\
\hline Health and welfare services for health care workers & V11 & 0.307 & 0.147 & 0.048 \\
\hline Development of innovation management processes & V12 & 0.285 & 0.076 & 0.041 \\
\hline $\begin{array}{l}\text { Ensuring the activity of human resources in accordance with standards and } \\
\text { regulations }\end{array}$ & V13 & 0.267 & 0.087 & 0.039 \\
\hline Training of health care workers & V14 & 0.244 & 0.068 & 0.037 \\
\hline Requirements & Abbreviation & $\begin{array}{c}\text { Level } \\
\text { Weight } \\
\end{array}$ & $\begin{array}{c}\text { Criterion } \\
\text { Weight }\end{array}$ & $\begin{array}{c}\text { Final } \\
\text { Weight }\end{array}$ \\
\hline Development of office automation & H1 & 0.398 & 0.325 & 0.132 \\
\hline Development of a comprehensive hospital information system & $\mathrm{H} 2$ & 0.359 & 0.311 & 0.117 \\
\hline Electronic health record & H3 & 0.321 & 0.242 & 0.096 \\
\hline Management information systems and decision support & $\mathrm{H} 4$ & 0.287 & 0.123 & 0.092 \\
\hline Integration of health information system & H5 & 0.271 & 0.096 & 0.083 \\
\hline Assurance to access accurate and timely information & H6 & 0.244 & 0.143 & 0.071 \\
\hline Integration of a common information system between employees & $\mathrm{H} 7$ & 0.216 & 0.078 & 0.065 \\
\hline
\end{tabular}

and welfare services for health care workers; development of innovation management processes; ensuring the activity of human resources in accordance with standards and regulations; and training of health care workers (Table 5).

Human capital participation priorities in the model of health economics management system include the follow- ing components: development of office automation; development of a comprehensivie hospital information system; electronic health record; management information systems and decision support; integration of health information system; assurance to access accurate and timely information; and integration of a common information 
system between employees (Table 6).

\section{Discussion}

In general, the results of the present study showed that the model of human capital development in the health system of Iran has the following priorities: health services management, human capital financing, improving human capital education, and human capital participation with several components. In a study by Behrman et al in 2019, researchers briefly reviewed the human resource development plan and the comprehensive staff training charter (11). In the development of human resources in the health sector, especially hospitals, human resource planning and training are key tasks (12). In another study in this regard, Nasiripour et al in 2011, designed the model of management development in social security hospitals and determined the dimensions and components of management development and concluded that in designing management development programs that are part of human resource development (12). It is necessary to pay attention to theoretical knowledge, acquired ability, and personality traits (13).

In general, according to studies, the most important factors affecting economic growth are labor, physical capital, and human capital. In general, the concept of human capital in economic literature includes education, health, skills (expertise), experience, migration, and other investments that increase labor productivity and thus increase economic growth. (14). Currently, most studies on human capital have focused on education as a measure of human capital and less attention has been paid to health. However, when it comes to improving the quality of the workforce, the issue is not limited to education, skills, and experience, as the health of individuals should be considered as a factor in the accumulation of human capital (15).

In many health care systems worldwide, much attention has been paid to human resource management (HRM). Human resources, when it comes to health care, can be defined as different types of clinical and nonclinical staff responsible for public and individual health interventions. As arguably the most important input to the health system, the performance and benefits of the system can depend to a large extent on the knowledge, skills, and motivation of those responsible for providing health services (16).

Both the number and cost of health care consumables (drugs, prostheses, and disposable equipment) are increasing astronomically, which in turn can dramatically increase health care costs. In public budget systems, the costs incurred in this area can affect the ability to hire and retain effective physicians. In both government and employer budget systems, HRM methods must be developed to find the right workforce balance and the ability of physicians to practice effectively and efficiently. A practitioner without sufficient tools is as inefficient as having tools without a physician (17).

The quality of health care is generally defined in 2 ways: technical quality and sociocultural quality. The technical quality refers to the impact that existing health services can have on the health conditions of a population. The sociocultural quality measures the acceptability of services and the ability to meet patients' expectations (18).

In this regard, Tabibi et al in 2016 studied the factors affecting the development of human capital in the hospitals of the "Social Security Organization" of Iran. By studying the patterns of human capital dlevelopment, the initial conceptual model was designed and approved by a survey of experts. Then, the questionnaire designed based on the initial model was completed by all those responsible for human capital development of the treatment management of the "Social Security Organization" on 68 people. Exploratory factor analysis was performed by the maximum likelihood method and variables were interpreted by the Varimax method. A confirmatory factor analysis was used to confirm the obtained factors, and the structural equation modeling method was used to determine the direct and indirect relationships of the components. Factors related to the component of commitment (organizational development and management commitment) were related to the factor determining the path of career advancement. The factor of determining the path of career advancement was directly related to the factor of education planning. The education planning factor was directly related to the factors of human capital development measures (education and personal development) and the evaluation factor was recognized as an independent factor influencing all factors. According to the findings, the factors identified in this study seem appropriate for the development of human capital in hospitals of the "Social Security Organization" (19).

In health care organizationis, physicians, nurses, and other caregivers must work together to meet the patient's needs and achieve positive health outcomes. Therefore, a healthy human capital management strategy includes mechanisms that encourage teamwork, transparency, and trust. When team members are open and honest with each other, it leads to mutual trust, cooperation, and sharing of best practices across disciplines, and patients will benefit the most (20).

Research shows the benefits of positive cognition as an important part of human capital management strategy. Lee et al in 2019 examined improving health and human capital through an effective primary care system. To improve the health of the population, it is necessary to reduce health inequalities and increase health protection and disease prevention, and timely diagnosis and treatment of diseases by dealing with health determinants in the downstream, middle and upstream. There is strong theoretical and empirical evidence for a link between strong national primary care systems and improved health indicators. The determinant approach to health promotion, such as healthy schools and healthy cities, also aims to address the determinants of health and build the capacity of individuals, families, and communities to establish strong human and social capital.

The concept of human and social capital explains why some societies are not able to achieve better health than others with similar demographics. In this article, a review of studies in different countries shows how a welldeveloped primary health care system can reduce all causes of death, improve health, and reduce hospitalization- 
despite the lack of differences in socioeconomic conditions. The intervention strategy recommended in this paper is developing a model of a comprehensive primary health care system by joining different settings and combining the efforts of different parties inside and outside the health sector. Then, the different components of the primary care team work more closely with individuals and families and different health conditions. This synergistic effect helps to strengthen the development of human and social capital. This model can then combine upstream, middle, and downstream efforts to improve population health and reduce health inequality. Otherwise, as a result of rapid urbanization, health is easily endangered (21). According to the results of other researches and present research, it has been observed that to date no research has been done on the requirements of human resource development effective in the country's health system and most researches have considered only one hospital or one ward. The use of the opinions of faculty professors in the field of research is also one of the strengths of the present research. However, the mental state of the participants during the interview and completion of the questionnaire was not under the control of the researcher, which might have affected the results of the study and is one of the weaknesses of this study.

\section{Conclusion}

According to the results, it is suggested to identify the future personnel needs of the health organization to enable the rational, useful, and optimal use of human resources for the organization and management and also to coordinate human resource activities with the organization's future goals and plans and reduce the organization's personnel costs. Moreover, it is suggested that an appropriate tax system and the observance of horizontal and vertical justice be established to address deficiencies in health sector financing.

\section{Conflict of Interests}

The authors declare that they have no competing interests.
8. Farahbakhsh M, Nikniaz AR, Tajadldini N, Entezar S, Hasanzade AR. Comparing Total Quality Managrement (TQM) and Management Effectiveness Program (MEP) in Improving of Health Facilities Management. J Health Admin. 2011 Jan 10;13(42):35-44.

9. Swanson RA. Human resource development and its underlying theory. Hum Resour Dev Int. 2001 Jan 1;4(3):299-312.

10. Delgoashaee B, Tabibi S, Pahlevan P. Designing a human resource development model for the health sector of Iran. Res Med. 2007;31(4):317-325.

11. Behrman JR. Early life nutrition and subsequent education, health, wage, and intergenerational effects. Health Growth. 2009;6:167-83.

12. Nasiripour AA, Raeissi P, Tabibi SJ. Development and compilation of strategies and preventive measures for medical errors in public hospitals in Tehran. J Health Admin. 2011 Jul 10;14(44):21-32.

13. Spence M, Lewis M, editors. Health and growth. The World Bank; 2009 May 29.

14. Mesbahi M, Tofighi S, Abbas ZA. Determining Approach to Human Recourse Development. Nurs Res. 2011; 6(2):17-29.

15. Lotfalipour MR, Falahi MA, Borji M. The effects of health indices on economic growth in Iran. J Health Admin. 2012 Jan 10;14(46):5770.

16. Becker BE, Huselid MA. Strategic human resources management: where do we go from here? J Manag 2006 Dec;32(6):898-925.

17. Damari B, Heidari A. Designing a Management Model for Development Plans in the Field of Health at the National, Provincial and the District Levels. J Community Health. 2017 Jan 1;4(4):260-68.

18. Bahrami M, Vatankhah S, Tabibi S, Tourani S . Designing a Health System Performance Assessment Model for Iran. Health Inf Manag. 2011; 8(3):3-5.

19. Tabibi SJ, Vatankhah S, Vahdat SH. Factors affecting the human capital development in hospitals of the Iranian Social Security Organization. J Inflam Dis. 2011 Jull 10;15(2):55-62.

20. Hall RE, Jones CI. Why do some countries produce so much more output per worker than others? Q J Econ. 1999 Feb 1;114(1):83-116.

21. Lee A, Kiyu A, Milman HM, Jimenez J. Improving health and building human capital through an effective primary care system. J Urban Health. 2007 May;84(1):75-8;5.

\section{References}

1. Alwan A, Hornby P. The implications of health sector reform for human resources development. Bull World Health Organ. 2002;80(1):56-60

2. Bates R. Improving human resources for health planning in developing economies. Hum Resour Dev Int. 2014 Jan 1;17(1):88-97.

3. Veld M, Paauwe J, Boselie P. HRM and strategic climates in hospitals: does the message come across at the ward level? Hum Resour Manag J. 2010 Nov;20(4):339-56.

4. Kabene SM, Orchard C, Howard JM, Soriano MA, Leduc R. The importance of human resources management in health care: a global context. Hum Resour Health. 2006 Dec;4(1):1-7.

5. Asghari Sarem A, Markazi Moghaddam N. Analysis of success crucial factors for human resource development at health sector. J Public Organ Manag. 2015;3(3):27-50.

6. Frotani Z, Azar A, Ahmadi A, Askarinejad M. Design and explain the self-development model of human resources. Manag Gov Organ. 2013;1(4):61-78.

7. Faraji Khiavi F, Maleki MR, Djafarian K, Vatan Khah S, Tabibi SJ. A comparative study on identifying core stages of policy-making in human resources for health: 2009. Jundishapur J Health Sci. 2012 Mar $31 ; 4(1)$. 